\title{
Investigation Motivation in School Performance of Students with Intellectual Disabilities: Views of General and Special Education Teachers
}

\author{
Zarifopoulou Anastasia \\ Early Childhood Teacher, Athens, Greece \\ Email: azareifopoulou18b@gmail.gr
}

How to cite this paper: Anastasia, Z. (2022) Investigation Motivation in School Performance of Students with Intellectual Disabilities: Views of General and Special Education Teachers. Open Access Library Journal, 9: e8421.

https://doi.org/10.4236/oalib.1108421

Received: February 3, 2022

Accepted: February 22, 2022

Published: February 25, 2022

Copyright () 2022 by author(s) and Open Access Library Inc.

This work is licensed under the Creative Commons Attribution International License (CC BY 4.0).

http://creativecommons.org/licenses/by/4.0/

(c) (i) Open Access

\begin{abstract}
The purpose of the research is to investigate the learning motivations of children with mental retardation, based on the views of teachers. The methodology used was mixed. This mixed research was the qualitative methodology, with a data collection tool, the semi-structured interview, and the quantitative methodology, using questionnaires. The sample consisted of four (4) general education teachers and 45 special education teachers. The research questions of the present study were: what is the level of interest of the student with mild mental retardation for lessons and school, what is the level of anxiety of the student with mild mental retardation in case of low performance, what are the motivations of the child with mild mental retardation that contribute to his active learning (positive or negative), according to the teachers and the last research question was whether the same teachers face difficulties in creating learning motivation in children with mild mental retardation, and If so, which ones. The results show that creating motivation for learning in children with mental retardation is difficult and demanding. General education teachers face more difficulties than special education teachers. In any case, the persistence and will of the teachers can bring the desired results.
\end{abstract}

\section{Subject Areas}

Special Education

\section{Keywords}

Motivation, Intellectual Disabilities, Special Education Teachers, Mainstream School Teachers, Integration, School Performance 


\section{Introduction}

The present study aims to investigate the role of motivation in the school performance of students with mental retardation. Motivation is an important factor in human behavior [1]. They are based mainly on the internal needs of the individual, directing him to a specific process, in order to achieve a goal. The creation of motivations is based mainly on human instincts and emotional needs [1]. The present study discusses how easy or difficult it is for a teacher to rely on the needs of a mentally retarded student in order to improve his/her performance in school. According to the "Diagnostic and Statistical Manual of Mental Disorders" (DSM-V) of the American Psychiatry [2] mental retardation is defined as the total mental disability or mental retardation, according to which the individual is deprived in relation to the typical stages of development.

The purpose of the research is to investigate the motivations of school performance of students with Mental Retardation, according to the views of teachers. It seems necessary to investigate the issue, as there are some obstacles and difficulties in the integration of students with mental retardation. The need to integrate these students may arise from their lack of motivation. More specifically, the views of general and special education teachers regarding the subject of the present study will be investigated. With their participation it will be noted whether a teacher has the ability to create learning motivation in children with mental retardation.

The research questions of the proposed research are the following:

- According to the teachers, what is the level of interest of the student with a slight mental retardation for the lessons and the school?

- According to the teachers, what is the level of anxiety of the student with mild mental retardation in case of low performance?

- What are the motivations of the child with mild mental retardation that contribute to his active learning (positive or negative), according to the teachers?

- According to teachers, they themselves face difficulties in creating learning motivation in children with mild mental retardation, and if so what are they?

The present research confirms or adds new data to the already existing Greek literature, as the researches that have been carried out are not modern. Cover potential gaps in the literature, as modern studies do not address the importance of motivating children with mental retardation regarding the learning process.

\section{Theoretical Framework}

Motivating students with learning difficulties is a very basic principle in the teaching process. The concept of motivation is based on the result of behavior performed consciously or unconsciously by the individual himself [3]. Motivation pushes students to maintain their attention and interest during learning. They are based on the personal need of the student, but also on the ability of the teacher to motivate the child to participate in the lesson, with the aim of developing cognitive skills. 
The creation of motivations is guided by the behavior of the individual, which is developed in a specific way, in order to achieve a specific goal [4]. Maslow [5] developed a theory, according to which the first human need is the one that affects motivation, creating a "hierarchy", based on levels of needs. Biological needs, such as food and water, are at the first level of needs and when they are met, they activate the next level. When the needs of all levels are met, then the individual can accomplish and become, whatever he can and desires [5]. The development of these stages is inextricably linked to the individual's education and teaching process [5].

Motivation is divided into internal and external [6]. Internal motivations are based on the personal interest of each individual with the aim of gaining satisfaction and knowledge. It is not affected by external factors and amplifiers. Internal motivations are those that strengthen the part of education [4]. External incentives are related to the material reward, or more generally the reward with the completion of any transaction. The student wishes to perform an act in order to receive the reward. The two types of motivation are associated with a common axis the acquisition of knowledge and experience [7].

The mental quotient is an integral part of the learning process. Mental quotient is defined as the mental age of the individual, is the level at which the child is, regardless of his chronological age [8]. An important reference for the comprehensive view of the subject of this study is the meaning of the term intellectual disabilities. Intellectual disabilities are related to the situation in which the person does not develop mentally, as a result of which he/she faces difficulties in adapting to the social environment, as the help from another member is necessary [9]. In addition, the mental retardation must have occurred to the individual for the first time before the age of eighteen [10].

The ICD-10 categorizes intellectual disability into mild, moderate, severe and severe form [11]. The causes are usually biological, but often the onset of intellectual disability is due to environmental and psychological factors. If a person is in the first category, then he is easily trained. In the moderate form, the person is trained with difficulties, while in the severe form, they are constantly monitored by specialized doctors and appropriate medication is administered. Finally, in the severe form, individuals have minimal motor skills and require constant care from another person [11]. In any case early intervention is always crucial, for their entire development [12].

The school environment and the learning process can be an important variable in the mental level of the child [13]. A child is influenced by his family, social and school environment. It is important that a child attends school, and how positively it can affect their intelligence. The conclusions that emerge are that the school environment can contribute positively to the improvement of intelligence [13].

Additional research reveals whether motivation affects the performance of students with intellectual disability. Initially, the research of [14], aims to study 
the effectiveness of various techniques in students who face difficulties in the learning process. Use a quantitative methodology with a tool to draw conclusions from the questionnaire. The results show that the majority of teachers argue that by implementing appropriate, specialized programs, students with disabilities can actively participate in the learning process.

In Moragianni's research [15], the performance of students at school is analyzed, in relation to the motivations they develop. Quantitative methodology was selected, using a questionnaire. The results show that there is a high performance of students who have developed internal motivation. The motivations they have positively shape their self-confidence and self-esteem, and they record a positive performance in school activities [15].

The above studies are complemented by the research of Flamiatou [4]. In this study, the issue of personality and learning motivation of 5th and 6th grade students is developed. The choice of methodology is equally quantitative. A questionnaire is used. The bottom line is that motivated students, whose learning interest is maintained, perform better than non-motivated students. Thus, they develop a sense of self-regulation, a fact that contributes positively to their performance, due to increased self-confidence [4].

The Magginas's [16] research examines whether students with intellectual disabilities understand math and other school activities. The methodology is mixed, using quantitative and qualitative tools, such as observation, interview and questionnaire. Considering the conclusions, it is obvious that students with intellectual disability find the mathematics lesson interesting, when it is done in combination with physical education. This means that students develop motivation and progress in school [16].

In Zisimopoulos's research study [17], the issue of students' internal motivations with learning difficulties is addressed and how this affects their performance in school. The researcher used a quantitative method, using the questionnaire as a tool. The conclusions that emerge show that students with learning difficulties easily show a loss of interest. When this happens, their school performance declines. On the contrary, in a pleasant learning environment, students' interests increase and make significant progress in school (Zisimopoulos, 2015) [17].

Another study analyzes the evaluation made by teachers regarding the attendance of students with intellectual disability in primary schools of special education [18]. A qualitative methodology, through semi-structured interviews in students and teachers, was employed. The conclusions state that students face difficulties in integrating into the school environment. The school unit does not support individualized programs, with the result that students do not perform well in school.

Finally, Ambrazi's research [19] was developed with a mixed methodology, qualitative and quantitative, using a questionnaire, interview and observation. The resulting conclusions follow opposite views compared to the two previous 
surveys. There seems to be difficulty in educating children with intellectual disability, and therefore in creating motivation, due to the marginalization that these children experience from the social environment. As a result, it is not easy to motivate these students. Consequently, it is very important to take into serious consideration parameters such as teachers' sentiments and concerns of inclusion, in order to deliver effective interventions [20].

Moreover, recent research data report high level of self-efficacy of special educators, which can assist their efforts to increase students' motivation [21]. Though, difficulties during COVID-19 crisis have been increased and create a difficult situation for all teachers working in special education [22].

From the report of previous research, it is clear that there are difficulties and problems in the learning process. Teachers are called upon to play an ongoing and active role in teaching students with intellectual disabilities in order to motivate them. In addition, there is a lack of motivation for students with intellectual disability in terms of their school performance. Therefore, this study fills the bibliographic gap, as it seems that there is not enough research in Greece, and recent, on the subject. It will contribute to the creation of new knowledge, researching the contribution of motivation to children with intellectual disability, according to the views of teachers.

\section{Research Methodology}

The present study is educational research. Educational research is an important tool for feedback on educational processes [23]. It can be considered as a means of information and the result of a teaching process. The main objectives of the implementation of educational research are the continuous information and training of teachers, the influence on educational policy and teaching [23].

In this research a mixed methodology was carried out. Mixed research is one of the scientifically recognized types of research [24]. It combines the techniques of qualitative and quantitative method. Thus, the results are better utilized and the deficits or weaknesses that may arise are addressed more effectively. For this reason, it is considered that this type of research offers the possibility of increasing the benefits of each research goal.

The results that usually result from quantitative research are objective, using an adequate sample for inferential statistics [25]. The aim of this type of research is to collect a variety of data, displaying new information based on the betterment of society. The design could be described as rigorous, as it is intended to carry out specific results.

The results of quantitative research are accurate and considered objective. Mathematical analysis is used, with the results showing specific statistical differences compared to previous surveys. This is done by the researcher, as it can be addressed to an adequate number of participants, regardless of age, gender or place of residence [25].

With qualitative research, the researcher is given the opportunity to share in 
depth the subjective views of the participants. This type of research answers the "why" and "how" questions. The researcher can use the research tools in such a way as to extract more information from the participant, without restriction. The qualitative method is characterized as more appropriate for the collection of information about the behavior of the individual [26].

From the above reports it seems that the choice of mixed methodology is the most appropriate. With the tools of any kind of research, more complete knowledge is added and more answers are given. In this way the comparison of views is made.

After studying the literature review and the study of the subject under investigation, the researcher concluded that the sample will be general and special education teachers. Forty-five (45) special education teachers and four (4) general education teachers participated. The disparity in the number of participants between ordinary and special teachers is explained by the method employed. Using a qualitative approach in a number of 4 four participants can provide sufficient data. The sample of the study provided the necessary demographic data, such as gender, age, years of service, studies and work context.

There was no leak. On the contrary, more participants were gathered, compared to the initial number. In completing the questionnaires, instead of 30 , there were 45 special education teachers.

Due to the mixed method followed by the research, sampling was performed in two ways. The first sampling strategy is intentional. A small number of samples were collected to make the results more reliable. The choice of participants is random; however, it is not based on the generalization of conclusions [27]. The first method of sampling concerns fourty-five (45) special education teachers, who were given a questionnaire. In the second method, random sampling was used. The sample is selected based on its availability. Participants volunteered and did not show consistency with the overall set of views. This characteristic makes the sample objective in its judgment and unprejudiced [28]. The sample in this selection concerns 4 general education teachers, who were interviewed.

The data were analyzed by comparison, due to different sources and results. This process leads to the analysis and interpretation of the answers, based on empirical facts, which were expressed objectively [29]. The additional deepening of the exploratory data, increases the rates of validity and reliability.

In addition, two research tools were used in the questionnaire and the semistructured interview. This questionnaire consists of 28 questions. The first five (5) are the demographic questions. Of the remaining twenty-three (23) questions, 20 are closed-ended and are presented in the form of a scale, where the participant chooses his answer. The remaining 3 are open type [29].

Through the interviews the views of special education teachers can be analyzed more phenomenologically, while in parallel with the use of the questionnaire there are more participations. The data are then compared in a valid and reliable way, through triangulation. 
It is worth mentioning at this point that the tools for conducting this research were drawn from the existing literature, but also in the tool of Entwistle, [30]: “Academic Motivation Self rating inventory" which was translated from English and adapted to Greek reality by Kakavoulis [31]. Both the questionnaire and the interview questions had emerged from a literature review and had already been selected for validity and reliability. Reliability and validity were based on the instrument with Cronbach's reliability coefficient $\alpha$ (alpha) and the value found from the results of the Reliability Analysis-Scale (Alpha) indicates a satisfactory degree of internal consistency (Alpha $=0.7543)$.

The research process for data collection, one (1), was from February 20, until March 20. The questionnaires were distributed through an electronic platform, and various social media, in order to gather the required participants. Due to the pandemic that has hit Greece, the interview process was carried out equally with the help of online media. SPSS was used to analyze the data of the questionnaire answers. The SPSS program processes the data, based on the commands that will be given and then encodes the results [32].

For the analysis and coding of the interview data, the thematic analysis was used, by descriptive method. Thematic analysis is a systematic organization and recognition of existing data, aiming at full understanding and detection of more information [29].

All personal data collected, both from the interviews and from the questionnaires, were used solely for the conduct of the survey and were not disclosed to third parties without our prior consent.

The reliability of the research is determined by the form of triangulation, due to the mixed methodology, which allows the use of two different tools. The concept of triangulation defines the use of different methods for the purpose of the same research study [33]. Each type of research method is used to verify the results with each other, through a comparative process. The process of triangulation provides a multidimensional creation of results, enriching the results with more data.

\section{Results}

The following chapter presents in detail the results obtained, both from the questionnaires and from the interviews. The method of analysis of the quantitative research data was performed with the SPSS program. The data collected from the interviews were coded by the method of thematic analysis.

\subsection{Questionnaire Data Analysis}

As shown in Table 1, the participants of the questionnaire were 40 women and 5 men. The majority of the age of the participants ranged from 22 to 32 years. Years of service did not appear to exceed 5 years, as the minority stated 16 years or more of service. Finally, $60 \%$ of the special education teachers who completed the questionnaire work in a general school. 
Table 1. Demographics of participants.

\begin{tabular}{cccc}
\hline & & Frequency & Percentage \\
\hline \multirow{3}{*}{ Gender } & Women & 40 & 88.9 \\
& Men & 5 & 11.1 \\
\hline \multirow{3}{*}{ Age } & $22-32$ years old & 23 & 51.1 \\
& $33-43$ years old & 14 & 31.1 \\
& 43 years and over & 8 & 17.8 \\
\hline \multirow{3}{*}{ Years of service } & $1-5$ & 19 & 42.2 \\
& $6-10$ & 8 & 17.8 \\
& $11-15$ & 9 & 20 \\
Type of school unit & Special school & 20 & 18.4 \\
& General school & 27 & 15.6 \\
\hline
\end{tabular}

\section{1st research question:}

In the first research question "what is the level of interest of the student with mild intellectual disability for the lessons and the school?", According to the teachers, out of the 45 participants, $62.2 \%(n=28)$ consider that it is not very high. The percentage opposes $33.3 \%(n=15)$ and $4.4 \%(n=2)$, to consider that the student's interest in school is very high and very high, respectively (Table 2). As shown in Table 2, 46.7\% ( $\mathrm{n}=21)$ of special education teachers, consider the participation of students with intellectual disability in the learning process very difficult, while $8.9 \%(n=4)$ not at all difficult.

The majority of teachers consider the participation of students with intellectual disability in the learning process important, with $77.8 \%(\mathrm{n}=35)$ considering it very important and only $22 \%(\mathrm{n}=10)$ considering it simply important (Table 2).

\section{2nd research question:}

In the second research question, "According to the teachers, what is the level of anxiety of the student with mild intellectual disability in case of low performance?", It seems that the majority of the 45 special education teachers consider that the level of anxiety is a bit low reaches $66.7 \%(n=30)$. The remaining percentage is equated to the parameters that teachers believe that the level of concern does not exist, or is more or less similar (Table 2).

However, 28 of the special teachers, with a percentage of $62.2 \%(n=28)$, believe that in case of stress, the student with intellectual disability can express his concern, while $37.8 \%(n=17)$ believes the opposite (Table 2$)$.

After analyzing the results, the reasons that the majority of teachers believe that the child with intellectual disability can express his level of anxiety are the following. 
Table 2. Results.

\begin{tabular}{|c|c|c|c|c|}
\hline Motivation and intellectual disabilities & NOT AT ALL & A LITTLE BIT & VERY & VERY MUCH \\
\hline Level of interest of a student with mental retardation & $0(0.0 \%)$ & $28(62.2 \%)$ & $15(33.3 \%)$ & $2(4.4 \%)$ \\
\hline $\begin{array}{l}\text { Difficulty in the participation of students with mental } \\
\text { retardation in the learning process }\end{array}$ & $4(8.9 \%)$ & $15(33.3 \%)$ & $21(46.7 \%)$ & $5(11.1 \%)$ \\
\hline $\begin{array}{l}\text { The participation of students with mental retardation in the } \\
\text { learning process is important }\end{array}$ & $0(0.0 \%)$ & $0(0.0 \%)$ & $10(22.2 \%)$ & $35(77.8 \%)$ \\
\hline Level of student concern, whether teachers believe it is low & $5(11.1 \%)$ & $30(66.7 \%)$ & $5(11.1 \%)$ & $5(11.1 \%)$ \\
\hline $\begin{array}{l}\text { Creating Learning Motivation in Students with Mental } \\
\text { Retardation } \\
\text { (Ease of creating motivation) }\end{array}$ & $5(11.1 \%)$ & $20(44.4 \%)$ & $20(44.4 \%)$ & $0(0.0 \%)$ \\
\hline $\begin{array}{l}\text { Creating Learning Motivation in Students with Mental } \\
\text { Retardation } \\
\text { (Difficulty of creating motivation) }\end{array}$ & $3(6.7 \%)$ & $28(62.2 \%)$ & $13(28.9 \%)$ & $1(2.2 \%)$ \\
\hline $\begin{array}{l}\text { Importance of developing motivation in students with mental } \\
\text { retardation }\end{array}$ & $0(0.0 \%)$ & $1(2.2 \%)$ & $8(17.8 \%)$ & $36(80.0 \%)$ \\
\hline Easy to create incentives by special educators & $1(2.2 \%)$ & $4(8.9 \%)$ & $32(71.1 \%)$ & $8(17.8 \%)$ \\
\hline Difficult to create incentives by general education teachers & $1(2.2 \%)$ & $4(8.9 \%)$ & $25(55.6 \%)$ & $5(33.3 \%)$ \\
\hline Difficulty in creating motivation & $0(0.0 \%)$ & $23(51.1 \%)$ & $21(46.7 \%)$ & $1(2.2 \%)$ \\
\hline $\begin{array}{l}\text { Vocational training and previous service } \\
\text { (Vocational training) }\end{array}$ & $0(0.0 \%)$ & $0(0.0 \%)$ & $7(15.6 \%)$ & $38(84.4 \%)$ \\
\hline $\begin{array}{l}\text { Vocational training and previous service } \\
\text { (Experience) }\end{array}$ & $0(0.0 \%)$ & $4(8.9 \%)$ & $11(24.4 \%)$ & $30(66.7 \%)$ \\
\hline Perception of student interests with mental retardation & $3(6.7 \%)$ & $35(77.8 \%)$ & $7(15.6 \%)$ & $0(0.0 \%)$ \\
\hline Ability of a special educator to deal with possible difficulties & $0(0.0 \%)$ & $2(4.4 \%)$ & $26(57.8 \%)$ & $17(37.8 \%)$ \\
\hline
\end{tabular}

Initially, each child in his own way can express his feelings, without this meaning that he will be able to communicate his concern with speech. It can be expressed through anxious behavior, body movements or expressions. In any case, the relationship that the teacher has with the student is important, so that he can perceive the emotional state of the student. In addition, the mental quotient of the child plays an important role. It is believed that children with mild mental illness express themselves much more easily than children with moderate or severe intellectual disability.

The results obtained from $37.8 \%$ of the participants who believe that the student with intellectual disability cannot express their anxiety are the following: first of all, special education teachers believe that the student with intellectual disability can not to perceive the situation he is in order to express his feelings. It is believed that the student's mental level affects his perception and emotional state. Finally, the cognitive skills, the level of interest of the student and the poor cooperation with the teacher, contribute negatively to the manifestation of emotions, by the student himself.

3rd research question: 
Regarding the third research question, "What are the motivations of the child with mild intellectual disability that contribute to their active learning (positive or negative), according to the teachers?", The initial information is that special education teachers believe that it contributes positively in the progress of students the creation of motivation, with $68.9 \%(n=31)$ considering that they contribute too much, and $31.10 \%(n=14)$ just too much. For this reason, 36 out of 45 teachers believe that it is important to develop motivation, while as shown in Table 2, it is not very easy to motivate students with intellectual disability.

Nevertheless, $80 \%$ of teachers believe that it is important to develop motivation for learning in students with intellectual disability regarding the learning process. The results are shown in detail in Table 2.

\section{4th research question:}

The last research question is: "According to teachers, they themselves face difficulties in creating learning motivation in children with mild intellectual disability, and if so, what are they?". Special education teachers believe that they find it easier to motivate themselves, children with intellectual disability, than general education teachers (Table 2).

It is believed that it is not very difficult to create and develop learning motivation in children with intellectual disability. According to the data in Table 2, the difficulty is on the "slightly" scale, at $51.1 \%$. Most people believe that their personal training and experience help them to be motivated. The majority of teachers seem to have little difficulty in understanding the student's interests, so that they can create learning motivation (Table 2).

The main obstacles that special education teachers face are the following: the majority of the 45 teachers report that the material means, the school infrastructure, the family environment, the emotional state of the child, the lack of interest of the student, but also of the teacher, contribute negatively to motivation. The minority argues that the obstacles presented mainly concern the material and technical means, the family environment and the lack of interest of the teacher.

Nevertheless, a large percentage of special education teachers believe that whatever difficulties they face, they can manage them (Table 2). This will benefit learning motivation in students with intellectual disability.

\subsection{Interview Data Analysis}

The participants were four women, three of whom are categorized in the age range of 22 - 32 years, and the fourth interviewed in the age range of 40 and over. All four interviewees are primary school teachers in general primary schools. Years of service range between 4, 13 and 33 years.

Regarding the first research question, what is the level of interest of the student, all the answers were based on the mental level of the student. More specifically, a child with mild intellectual disability may show interest in the learning process when it concerns the student's personal interests. However, there are 
times when the student often finds the teaching process indifferent.

The above results from the following:

Participant 1:

"... Thinking of the student I met, who was diagnosed with mild mental retardation, yes he clearly showed interest in the activities and topics we approached, especially when they related to dinosaurs, the solar system and computers...his favorite topics."

Participant 3:

"...I believe that as things are at school, the learning process often becomes tedious, both for children who are more diligent and like it, and for children who have any problem. Especially for these kids! The process is very boring."

The interviewees' answers are half in agreement with the results from the questionnaires (Table 2). The student's mental level affects the student's performance and interest, as shown by previous research. As mentioned [9] [15] an important factor for the acquisition of knowledge is the level of intelligence of the individual and his interest in learning depends on motivation. When the learning object corresponds to the mental level of the student, then interest is created for teaching. However, the level of interest of children with learning disabilities decreases systematically when their school performance decreases [17].

The second research question refers to the level of anxiety of the student with mild intellectual disability in case of low performance. Three of the general education teachers agree that the child with mild intellectual disability may express his/her concern in case of possible failure in the learning process. One of the teachers argues that many times students with intellectual disability can't express their anxiety, due to the cognitive level they are at.

The above results from the following:

Participant 2:

"Based on my experience so far, yes, I find that children with mental retardation feel anxious or worried about their performance. Surely when they succeed, they rejoice, while when the opposite happens, they feel disappointed. So yes, $P m$ just thinking that because they want to succeed, they' re anxious or worried about their success at school."

Participant 4:

“... They can't immediately understand the need they have at the moment and how to express it, and how to manage it. So, it may be a little harder for them to express exactly what they want."

As can be seen from the data obtained from the answers of the questionnaire participants in Table 2, they seem to agree with the view of the 4th participant, contradicting the opinions of the other interviewees. When motivation is created in the student, then he acquires interest in the lesson. Inductive, attributes to the learning process. As a result, the student can express possible frustration in case of failure [4]. According to the research, it is claimed that children with intellectual disability in case of failure express their feelings, as can be seen from the answers of the interviews. 
According to all interviewees, it is difficult to perceive the emotional state of students with intellectual disability. There are, however, times when their facial expressions, or the attitude of their behavior, indicate dissatisfaction.

The above results from the following:

Participant 3:

"It is difficult, because the right relationship must be created with each child. And when a class is large and each child has different topics, you must on the one hand formally, in your duties be perfect and take out a specific material, the hours do not arrive...it is difficult to deal especially with some children and to create this piece that they will trust you, so that they can show you their special pieces..."

Participant 4:

"... Usually, they express it with facial expressions. That is, you see that he may be disappointed, or not in the mood to participate in a course or activity, he may participate once but not more. Rare are the cases where he can express it with a lot of anger or make an explosion."

This conclusion confirms the data obtained from the answers to the questionnaire (Table 2), as $62.2 \%$ of special education teachers believe that the student with mild intellectual disability can express his/her concern in ways that can the teacher to perceive them, such as a strong expression on the face.

The third research question refers to what are the motivations of the child with mild intellectual disability that contribute to his active learning (positive or negative). According to general education teachers, motivations are divided into internal and external. They argue that internal motivations are more important in their creation, and that they are based entirely on the character and personality of the child. In addition, motivation is based on the student's interests. Therefore, the association of the lessons with favorite activities, dolls, students' faces, contributes to the smooth learning process.

The above results from the following:

Participant 4:

"... The truth is that external motives are easier to create and render, in the form of, say, giving a sticker, or a painting [...] internal motives are essentially... have to do with character of the child and is source...they work, when you cultivate them, the children now conquer them and they function reflexively, when required."

Participant 2:

"...In mathematics I make problems related to football, because I had a student with a slight mentality and he was only interested in that. So, through his interest, he could also focus on math."

The above data agree with the results of the questionnaire, as the majority of teachers argue that creating motivation is demanding (Table 2), but not impossible, as long as they are based on the interests of students. Internal motivations strengthen the part of education [4]. Through recent research, it seems that the family environment "self-defined" is the main motivation for active partici- 
pation of students in school [13]. In addition, when students' interest is combined with the learning process, then they develop learning motivation, and therefore a positive development in school [16].

An additional study, however, describes the attendance of mentally retarded children in general schools. The lack of individualized programs in general schools reduces the performance of students with low mental quotient [18]. As a result, the attendance of these children has a negative effect. Immediately, it is concluded that this research contradicts the above information.

The last research question refers to the possible difficulties of general education teachers in creating learning motivation in children with mild intellectual disability. Respondents unanimously target school structures, as they are deemed unsuitable to accommodate and integrate mentally retarded students into them. In addition, the logistics, the school environment, the cost, the lack of qualified staff from the general schools and the family environment. All of the above are the main obstacles that general education teachers face, which make their work in the classroom difficult.

The above results from the following:

Participant 2:

"...Imagine that this configuration of the environment is most often forced by the teacher and at his own expense. Think how much money is needed for all this! And for how much the teacher will be able to have his own money to be able to make paintings, emoticons..."

Participant 4:

"...the school does not operate co-ancillary. It does not help. And not because the schools do not want it, the principals do not want to give the money, it is really because the principals do not have the resources to use it so that they can help you."

"...a child with mental health should have a parallel support by his side. A teacher, who will be next to him and in parallel with the teacher of the class to inspire and coexist when some additional motivation is needed, to have collaborated with the teacher of the general, in order to work on this part."

The resulting data are in agreement with the results of the questionnaires, which were analyzed thematically, as the special education teachers agree on the obstacles they encounter, with the largest percentage claiming that the obstacles they encounter concern the material means, the school infrastructure, the family environment, the emotional state of the students and the lack of interest of some teachers.

As can be seen from the literature review, the barriers that are created are due to the emotional state experienced by students with learning difficulties, the non-supportive family environment and the indifference of teachers [19].

\section{Conclusions}

It is obvious that the need for education does not cease to exist in the presence of difficulties. Some students need more motivation to be actively involved in the 
learning process. As the results of the present research study showed, mental quotient and level of intellectual disability significantly affect motivation. It is clear that both special education teachers and general education teachers always strive for the best result.

From the data of the findings, teachers in Greece face many difficulties. Some of these are the lack of material resources, the inappropriate school structures, the poor cooperation with the parents, and often the teachers themselves. Many of the teachers do not have the appropriate vocational training so that they can cope in cases where their student has special learning difficulties, or other disabilities. As a result, the teacher does not care to motivate the student to teach, or simply fails and distances himself.

The above conclusions lead to the wrong course of the educational process that should be followed normally. The results show that despite the difficulties of teachers, the majority of them are willing to maximize their potential in order to integrate all children in the learning process. Each of the participants, regardless of specialty, wants to motivate students with intellectual disability. It tries to understand the interests of the children, in order to make the teaching more enjoyable for them. In conclusion, it is certain that there are several difficulties in motivating students with intellectual disability. Nevertheless, teachers manage to activate the internal motivations and create a pleasant learning atmosphere.

The results obtained from the present research signal the achievement of its purpose. The research data cover several gaps in the literature review. Research into motivating students with intellectual disability is not very recent. As a result, the information on the subject is outdated and thus does not correspond to modern reality. In addition, not much information on the subject is reported in the modern Greek literature. There are several references to intellectual disability as well as learning motivation. There are not enough issues to cover how one affects the other. Therefore, the present research brings new findings, while strengthening the existing literature.

Due to the situation prevailing in Greece, due to the pandemic, Covid-19, the research was not carried out within the framework defined by the research process. This was a problem, as there were several restrictions and obstacles to its implementation. The questionnaires were conducted with the help of social media. An additional obstacle was time. The time spent on the research was limited, and specific, as it was implemented in the context of a dissertation.

The above, resulted in the possibility of generalization, due to a small sample. However, the results of the present study can be compared and generalized only for cases of population that are similar to the sample.

\section{Conflicts of Interest}

The author declares no conflicts of interest.

\section{References}

[1] Koutsogiannopoulou, S. (2020) The Relationship between Learning Style and Learn- 
ing Motivation in Self-Regulated Learning of Teachers as Adult Learners. Master's Theses, Greek Open University, Patras. https://apothesis.eap.gr/handle/repo/49613

[2] American Psychiatric Association (2013) DSM-V. Diagnostic and Statistical Manual (Fifth Edition). American Psychiatric Association, Washington DC.

https://doi.org/10.1176/appi.books.9780890425596

[3] Kouti, E. (2018) Motivation in Music Learning: Exploring the Motivations of Adolescent Students Regarding the Study and Study of the Piano. Master's Theses, University of Macedonia, Thessaloniki.

https://dspace.lib.uom.gr/bitstream/2159/21709/4/KoutiEvangeliaMsc2018.pdf

[4] Flamiatou, A. (2020) The Personality and Learning Motivations of 5th and 6th Grade Students in Their Self-Regulated Learning. Master's Theses, University of Patras, Patras. https://nemertes.library.upatras.gr/jspui/handle/10889/13195

[5] Maslow, A.H. (2011) Motivation and Personality (Motivation and Personality). Aiora, Athens.

[6] Boekaerts, M. (2002) Motivation to Learn. https://unesdoc.unesco.org/ark:/48223/pf0000128056

[7] Kakakliouras, I. (2018) Investigation of the Relationship between Internal and External Learning Motivations and Metacognitive Skills in Students of Primary and Secondary Schools in Agrinio, Etoloakarnania. Master's Theses, Open University, Milton Keynes. https://apothesis.eap.gr/handle/repo/39811

[8] Vlachos, F. and Bonoti, F. (2020) Handedness and Cognitive Abilities. Scientific Annals, 13, 1-23. http://ejournals.lib.auth.gr/psyannals/article/view/7737

[9] Deli, P. (2015) Development of Teachers' Skills in Special Education and Training, for the Management of Problems with Students with Complex Cognitive, Emotional and Social Difficulties and in Their Families. Master's Theses, Univeristy of Pelopponisos, Tripoli.

[10] Charitaki, G., Soulis, S.G. and Tyropoli, R. (2021) Academic Self-Regulation in Autism Spectrum Disorder: A Principal Components Analysis. International Journal of Disability, Development and Education, 68, 26-45. https://doi.org/10.1080/1034912X.2019.1640353

[11] Koutrouki, A. (2019) The Self-Efficacy and Conscientiousness of Caregivers of People with Mental Retardation. Master's Theses, Hellenic Open University, Patras. https://apothesis.eap.gr/handle/repo/42949

[12] Charitaki, G., Tzivinikou, S., Stefanou, G. and Soulis, S.G. (2021) A Meta-Analytic Synthesis of Early Numeracy Interventions for Low-Performing Young Children. SN Social Sciences, 1, Article No. 105. https://doi.org/10.1007/s43545-021-00094-w

[13] Christakis, K. (2013) Teaching Programs and Strategies for Children and Adolescents with Mental Retardation. 3rd Panhellenic Conference on Special Education with International Participation, Athens, 1-3 March 2013, 128-136. http://users.sch.gr/nikbalki/files/Synedria/3syneae.pdf

[14] Athanasiadou, V. (2017) Teachers' Views on the Effectiveness of Teaching Methods of Reading to Students with Mild Educational Needs and Their Teaching Choices in Educational Practice. Master's Theses, University of Macedonia, Thessaloniki. https://dspace.lib.uom.gr/handle/2159/20434

[15] Moragianni, M. (2017) Study of Students' Performance in Natural Sciences Regarding Motivation and Active Participation. PISA 2015 Data Analysis. Master's Theses, Harokopio University, Kallithea.

http://estia.hua.gr/file/lib/default/data/19658/theFile 
[16] Maggina, I. (2011) The Understanding of Mathematics by Children with Mild Mental Retardation through an Interdisciplinary-Combined Program of Special and Physical Education Activities. Master's Theses, National Kapodistrian University of Athens. https://ir.lib.uth.gr/xmlui/bitstream/handle/11615/44871/9585.pdf?sequence $=1$

[17] Zisimopoulos, D. (2015) Internal Learning Motivation and School Performance with Learning Difficulties. Pedagogical Supervision, 47, 44-52.

https://ojs.lib.uom.gr/index.php/paidagogiki/article/view/6993

[18] Stagiopoulos, P. (2015) The Evaluation of Educational Programs for Students with Problems in Their Mental Development Who Attend Primary Schools. Master's Theses, Aristotle's University, Serres. https://www.didaktorika.gr/eadd/handle/10442/36370

[19] Ambrazi, Z. (2013) The Views of the Teachers of the Integration Departments for the Education of the Students with Mental Disability in the General School. Master's Theses. Aristotle's University, Serres.

[20] Vogiatzi, X.A., Charitaki, G. and Kourkoutas, E. (2021) Assessing Psychometric Properties of the Sentiments, Attitudes and Concerns about Inclusive Education Scale in a Greek-Speaking Sample of In-service Teachers. Technology, Knowledge and Learning.

[21] Antoniou, A.S., Geralexis, I. and Charitaki, G. (2017) Special Educators' Teaching Self-Efficacy Determination: A Quantitative Approach. Psychology, 8, Article ID: 1642-1656.

[22] Tzivinikou, S., Charitaki, G. and Kagkara, D. (2021) Distance Education Attitudes (DEAS) during Covid-19 Crisis: Factor Structure, Reliability and Construct Validity of the Brief DEA Scale in Greek-Speaking SEND Teachers. Technology, Knowledge and Learning, 26, 461-479.

[23] Charisiadis, S. (2010) Educational Research and Teachers in Greece. Are They in Dimension? Master's Theses, University of Thessaly, Thessaly. https://ir.lib.uth.gr/xmlui/bitstream/handle/11615/41848/9206.pdf?sequence $=1$

[24] Bania, T.A., Gianniki, M., Giannakoudi, S., Charitaki, G., Matzaroglou, C. and Billis, E. (2020) The Interaction with Disabled Persons Scale: Evidencing Construct Validity with Factor Analysis and Measurement Invariance in Greek-Speaking Healthcare Students. Disability and Rehabilitation.

[25] Kyriazopoulos, P. and Samanda, E. (2011) Diplomatic Research Methodology. Pedio, Athens.

[26] Bellali, Th. and Papazoglou, E. (2015) The Qualitative Methodology in Nursing Research. National Nurses Association of Greece, Athens.

[27] Isari, F. and Pourkos, M. (2015) Qualitative Research Methodology. Association of Greek Academic Libraries, Athens. https://repository.kallipos.gr/handle/11419/5826

[28] Lagoumintzis, G., Vlachopoulos, G. and Koutsogiannis, K. (2015) Chapter 4. Data Collection Methods. In: Koutsogiannis, K., Ed., Research Methodology in Health Sciences, Association of Greek Academic Libraries, Athens, 136-148. http://hdl.handle.net/11419/5360

[29] Papageorgiou, G. (2014) Data Collection Methods. Electronic Book. https://repository.kallipos.gr/bitstream/11419/5360/1/01 chapter_04.pdf

[30] Entwistle, N.J. (1968) Academic Motivation and School Attainment. British Journal of Education Psychology, 38, 181-188.

https://doi.org/10.1111/j.2044-8279.1968.tb02003.x 
[31] Kakavoulis, A.K. (1984) The Transition of Students from Primary to Secondary Education. Psychological and Pedagogical Consequences. Empirical Research on Students, Parents and Teachers. Doctoral Thesis, University of Thessaly, Athen.

[32] Fachiridis, G. (2014) Introduction to SPSS for Windows. Democritus University of Thrace, Komotini. https://www.ucy.ac.cy/hr/documents/2012/SPSS 13.pdf

[33] Evangelou, E. (2015) The Use of Methodological Triangulation in the Research of the Quality of Life of the Mentally Ill Living in the Community. E-Journal of Science and Technology, 1, 113-120. http://e-jst.teiath.gr/ 